\title{
O AMICUS CURIAE E O ASSISTENTE SIMPLES NA CONSTRUÇÃO DO PRECEDENTE
}

\section{Luís Carlos de Sousa Amorim ${ }^{1}$}

\section{RESUMO}

$\mathrm{O}$ artigo em tela trata do princípio do contraditório sob uma nova perspectiva, a saber, como fundamento que garante a ampla participação de terceiros interessados na construção da norma geral presente numa decisão judicial através da figura do amicus curiae e do assistente simples. Aproveita-se para demonstrar que, embora esses institutos sirvam para a otimização do princípio democrático no processo, são entre si distintos e garantem poderes processuais igualmente diversos. Assim, redimensiona-se o princípio do contraditório para abarcar a ratio decidendi de uma decisão.

Palavras-chaves: Amicus curiae; assistente simples; precedente judicial; Common law; democracia.

\section{THE AMICUS CURIA AND THE SIMPLE ASSISTANT IN CONSTRUCTION OF THE PRECEDENT}

\begin{abstract}
The article on screen deals with the principle of the adversarial in a new perspective, namely, as a basis that guarantees the wide participation of third parties interested in the construction of the general norm present in a judicial decision through the figure of amicus curiae and Simple assistant. It is used to demonstrate that, although these institutes serve to optimise the democratic principle in the process, they are distinct from each other and guarantee equally diverse procedural powers. Thus, the principle of the adversarial is resized to encompass the decidendi ratio of a decision.
\end{abstract}

Keywords: Amicus curiae; simple assistant; judicial precedent; Common law; democracy.

\section{INTRODUÇÃO}

Pelo modelo democrático todas as manifestações do Estado devem contar com a participação popular. É exatamente isso que diferencia democracia de autocracia, caracterizada pelo distanciamento daqueles que produzem a norma e seus destinatários. A democracia exige que os indivíduos participem da vida política de seus país e todo e qualquer processo de formação de norma em um Estado Democrático deve prever um procedimento que permita a participação dos cidadãos.

É assim, por exemplo, no processo legislativo em que os parlamentares são eleitos pelo povo e devem realizar consultas e audiências públicas nas mais diversas questões. Isso

\footnotetext{
${ }^{1}$ Mestrando em Direito Público pela Universidade Federal da Bahia - UFBA. Formado em Direito pela mesma instituição. Advogado. Email: luisc_amorim@hotmail.com
} 
também ocorre com o Poder Judiciário quando o juiz prolata uma decisão. A participação das partes concretiza o princípio democrático.

Deve ser assim também no processo de construção de precedentes judiciais. $O$ princípio do contraditório deve ser ampliado, permitindo maior abertura e pluralização do debate na formação da tese que se projetará em casos vindouros. A partir dessa ideia é possível a intervenção do assistente simples e do amicus curiae para fornecer maiores elementos de conhecimento ao órgão julgador.

Esses dois institutos, embora se aproximem são distintos, como se pretende demonstrar, de modo que, embora se exija menos requisitos para a intervenção do amicus curiae, o assistente goza de maiores poderes processuais, o que lhe dá maior poder de influência na construção da tese.

\section{A NECESSIDADE DE REDIMENSIONAMENTO DO PRINCÍPIO DO CONTRADITÓRIO E DA NOÇÃO DE INTERESSE JURÍDICO}

Tradicionalmente, o contraditório sempre foi visto como o direito das partes de informação-reação. Bastava-se assegurar a participação dos indivíduos nos atos que compõe o procedimento para que se entendesse como garantido o princípio do contraditório. Nessa perspectiva, explica Antônio Cabral que "a contraposição dialética de argumentos e teses eram o cerne do princípio"; não era necessária a aferição da interferência concreta que os argumentos lançados teriam em relação à atividade judicial (CABRAL, 2010, p. 104). Era suficiente a promoção do contraditório formal, isto é, do direito de integrar o processo, de ser comunicado acerca dos atos processuais e de sustentar oralmente em audiência (DIDIER JR. 2011, p. 56).

No entanto, assim como tudo na vida avança, também não mais se mostra suficiente o conceito de contraditório como mero direito de participação no processo. Hoje, o contraditório é visto também na sua dimensão substancial, consistindo em verdadeiro poder de influência. Ou seja, a atualidade demonstra que a simples manifestação no processo é insatisfatória, sendo necessário que haja reais possibilidades de influência no convencimento do magistrado (DIDIER JR. 2011, p. 56).

Rompe-se, dessa forma, com o paradigma tradicional do contraditório, consagrando-se um modelo que resulta da aplicação do princípio democrático no processo, uma vez que a 
democracia exige a criação de meios que garantam a efetiva participação dos cidadãos nas estruturas de poder do Estado. O contraditório passa a ser o instrumento que permite a comunicação recíproca entre as partes e o juiz, agente político do Estado.

Ademais, não é raro perceber a discussão, em artigos e manuais mais atualizados, acerca do contraditório cooperativo. Essa nova faceta do contraditório está alinhada ao princípio da boa-fé processual e ao dever de cooperação, fazendo com que a participação das partes em juízo também tenha como finalidade a colaboração na realização da atividade jurisdicional. O processo passa a ser entendido dialogicamente e as partes passam a desempenhar importante função no aperfeiçoamento do provimento jurisdicional que, por sua vez, deixa de ser um produto individual (DINAMARCO, 1987. p. 90).

A partir de então, toda a estruturação processual se constrói intersubjetivamente e a sentença ou acórdão passam a ser enxergados como resultado de uma comunidade dialética de trabalho. Seja qual for a posição ocupada pelo sujeito processual, a sua conduta deve convergir para um mesmo objetivo, qual seja, o de solucionar o conflito da melhor maneira possível (GONÇALVES, 2013, p. 209). É o que dispõe o art. $6^{\circ}$ do CPC quando estabelece que "todos os sujeitos do processo devem cooperar entre si para que se obtenha, em tempo razoável, decisão de mérito justa e efetiva".

Percebe-se, pois, que o contraditório cooperativo potencializa a dimensão substancial do princípio do contraditório e se amolda ainda mais ao sistema axiológico do neoconstitucionalismo ou formalismo-valorativo.

Fica claro que essa nova acepção do contraditório está diretamente ligada ao dever de motivação da decisão judicial, uma vez que será nela que o juiz exporá a contribuição de cada um dos litigantes na construção da sua decisão. Após lançar mão do aparato democrático produzido pelo novo pensamento constitucional, será o momento de o magistrado demonstrar como, de fato, a participação das partes influenciou na solução do caso.

Nesse sentido, o órgão jurisdicional passa a assumir duas posições, mostrando-se paritário com as partes na condução do processo e assimétrico (superior às partes) no momento da decisão (MITIDIERO, 2009, p. 102-103).

Ocorre que esta motivação carrega em si um entendimento jurídico que, além de servir como fundamento para o dispositivo da decisão que regula as partes que atuam no processo, se projeta também sobre inúmeras outras relações jurídicas titularizadas por sujeitos que em 
nenhum momento puderam participar da sua construção. Isso se dá principalmente por causa dos efeitos vinculantes ou, quiçá, persuasivos do precedente judicial.

Tal realidade é resultado do fato de a doutrina, historicamente, somente se preocupar em compatibilizar as multifuncionalidades do contraditório (MITIDIERO, 2007, 108-109). à norma individualizada presente no provimento decisório, esquecendo-se da norma geral. Até então, o contraditório tem sido visto como a simples garantia de resolução de um caso concreto mediante a participação efetiva dos sujeitos diretamente envolvidos na relação processual (DIDIER JR., 2011, p.399).

Entretanto, toda a construção teórica sobre o princípio do contraditório, aplica-se da mesma forma ao indivíduo que tem interesse na formação do precedente judicial que será aplicado em casos análogos como o seu. A segunda metade Enunciado 459 do Fórum Permanente de Processualista Civis - FPPC assevera esse entendimento ao preconizar que as normas "sobre a observância somente dos argumentos submetidos ao contraditório são aplicáveis a todo o microssistema de formação dos precedentes”.

Por isso, não há necessidade de uma nova concepção do princípio do contraditório, forjado especialmente para a norma geral de uma decisão, sendo suficiente o redimensionamento do instituto à luz do reconhecimento da teoria dos precedentes no ordenamento pátrio.

Todo e qualquer precedente deve passar pelo crivo do contraditório, não sendo possível a utilização de argumentos que não foram objeto do devido debate na sua construção, conforme prevê o Enunciado n. 02 do - FPPC.

Neste prisma, o novo estágio evolutivo do contraditório, adequado que está ao formalismo-valorativo, não apresenta divergência. Com efeito, as formas e atos processuais não podem ser concepções axiologicamente vazias (CABRAL, 2010, p. 208). Os institutos processuais materializam valores e, por sua vez, o contraditório cooperativo materializa ao máximo a ideia de democratização do processo, de modo que nenhuma incompatibilidade apresenta com o amplo direito de participação na construção de uma tese jurídica, desde que estabelecidos critérios que evitem a chicana processual.

São diversos os enunciados do FPPC que corroboram com esse pensamento (Enunciados 02, 376, 378, 459 e 522). A exemplo, o Enunciado 460 diz que “o microssistema de aplicação e formação dos precedentes deverá respeitar as técnicas de ampliação do 
contraditório para amadurecimento da tese, como a realização de audiências públicas prévias e participação de amicus curiae".

Sendo assim, faz-se interessante pontuar três aspectos que demonstram que a exigência do contraditório cooperativo ou participativo relaciona-se também à ratio decidendi. São eles: o caráter publicista do processo; o abandono da visão egoística do processo; e a vedação à não surpresa.

É imperioso relembrar que o contraditório passou a ser visto como um instrumento de colaboração das partes na resolução de um conflito. Isso significa que o princípio está em harmonia com os objetivos estatais da jurisdição, o que demonstra a sua face publicista (BARBI, 2010, p. 266) desenvolvida com o neoprocessualismo. Esse caráter demonstra que o processo passou a ser concebido como um espaço de discussão, que permite a exposição de argumentos que convirjam para a solução da controvérsia (relação entre as partes processuais) e para a formação do entendimento jurisprudencial (que deve se dar com a ampla participação dos setores da sociedade).

Se no que tange à norma individual, que diz respeito a um número bem restrito de sujeitos, preza-se pela observância de uma estrutura dialógica que faça com que o dispositivo da sentença seja resultado da interação estabelecida entre as partes e o juiz, mais razão há para se considerar que a ratio decidendi deve ser construída democraticamente, com a participação daqueles que podem sofrer a sua incidência.

Em segundo lugar, o dever de colaboração faz com que o processo não mais seja visto como um palco de lutas egoísticas entre as partes (COELHO, 2011, p. 46), de modo que elas devem atuar no sentido de ajudar no alcance da solução do caso, além de contribuir e permitir a contribuição de terceiros na formação da ratio decidendi, mormente quando se tratar de questão de maior relevância e repercussão social. Nesse sentido dispões o novo CPC em seu art.378 que "ninguém se exime do dever de colaborar com o Poder Judiciário para o descobrimento da verdade".

Por certo, o dogma de que somente pode se manifestar no processo aquele que está no âmbito de incidência dos efeitos da norma individual não mais subsiste (CABRAL, 2010, p. 105). Por vezes, os sujeitos que atuam no processo têm como único objetivo o aperfeiçoamento e legitimação da decisão jurisdicional. É o que ocorre, e.g., com o amicus curiae, cuja atuação não se baseia em potencial prejuízo que sofreria caso não interviesse no 
processo, mas sim na necessidade de qualificação e democratização da decisão judicial (WAMBIER; MEDINA, 2010, p. 494).

Por último, a relação entre o contraditório cooperativo e o princípio da boa-fé garante a todos os sujeitos processuais o direito de não ser surpreendido. Isso é aplicável às partes, que não podem adotar comportamentos antiéticos no sentido de ludibriar o adversário a todo custo (até porque o mesmo princípio estabelece o dever de lealdade); ao magistrado, que não pode quebrar as expectativas geradas pelo seu comportamento no processo (DIDIER JR, 2011, p. 85) (nesse sentido, discorre o enunciado 376 que "A vedação do comportamento contraditório aplica-se ao órgão jurisdicional"); e ao procedimento de formação do precedente judicial, exigindo que os setores da sociedade tenham prévia possibilidade de interferência em sua elaboração, seja por meio de audiências públicas, intervenção de amicis curiae ou de assistente simples.

$\mathrm{Na}$ maioria das vezes, as técnicas estabelecidas pela teoria do precedente não permitem ao jurisdicionado a possibilidade de esquivar-se da incidência de uma ratio decidendi firmada em um julgado anterior. Isso porque, ou não estão presentes as peculiaridades que permitem a distinção entre o caso sub examine e o caso paradigma, ou não se verificam os requisitos necessários à superação do precedente judicial por meio do overruling.

Nesses casos, tratando-se de precedente vinculante, o jurisdicionado não terá nenhuma possibilidade de discutir a justiça da ratio decidendi que será aplicada de maneira obrigatória no processo de que participa ou venha a participar. Com isso, é indubitável que o seu direito ao contraditório está sendo duplamente violado. Primeiro, porque é surpreendido por um entendimento jurídico que não ajudou a construir (contraditório cooperativo). Segundo, porque perde o efetivo poder de interferência no processo em que atua (contraditório substancial), já que o precedente vincula a decisão do juiz.

Destarte, sendo a razão de decidir de um caso concreto a norma a ser aplicada em um processo futuro, a fim de que se resguarde a garantia do contraditório, é de todo recomendável que se oportunize a ampla participação da sociedade. Caso contrário, mitigado estará o direito que têm os futuros litigantes de influir no convencimento do magistrado que julga o seu processo (ARENHART, 2007, p. 425).

Além do redimensionamento do contraditório, é necessário também que a noção e a amplitude do interesse jurídico sejam também redefinidas. Até então, assim como o princípio 
do contraditório, o interesse jurídico sempre foi pensado a partir da norma individualizada. A sua função sempre foi a de garantir a participação dos indivíduos que poderiam ser prejudicados no estabelecimento da regra do caso.

Foi nessa lógica que surgiram duas das modalidades de intervenção de terceiros, que, inclusive, mitigaram a regra de que o processo somente diz respeito às partes (assistência e do recurso de terceiro prejudicado). Ao lado de outras categorias (como as demais modalidades de intervenção de terceiro; a restrição da eficácia subjetiva da coisa julgada e a permissão de processo incidentes, como os embargos de terceiro (DIDIER JR, 2011, p. 350), elas representam um esforço do ordenamento para coibir a ultra-eficácia da sentença.

Ocorre que, do mesmo modo que a noção de interesse sempre esteve atrelada à norma individual, a ocorrência de prejuízo jurídico nunca levou em consideração os efeitos gerados pela norma geral. O resultado disso é que qualquer interferência da orientação de um julgado na vida de um indivíduo era tida como irrelevante, não lhe legitimando para atuar no processo.

O modelo processual da atualidade impõe, porém, o abandono de dogmas que limitam a expansão da participação democrática. Nessa perspectiva, nos casos em que o conceito de prejuízo é o único fundamento para a intervenção, a sua compreensão deve ser alargada para abarcar os prejuízos que uma ratio decidendi pode gerar. Afinal, as relações jurídicas desenvolvidas pelos sujeitos que não estão no processo também são alteradas pelo provimento decisório.

Nesse sentido, a eficácia reflexa da decisão que somente embasava a possibilidade de intervenção de terceiros na discussão da norma individual passa embasar também a participação na razão de decidir, de modo que se aperfeiçoa a ideia de interesse jurídico reflexo.

Priscila de Jesus aponta que alguns autores já se debruçaram sobre a necessidade de redefinição do interesse jurídico para fins de intervenção assistencial (JESUS, 2014, p. 216223). Robson Renault Godinho defende que haverá interesse institucional do Ministério Público, apta a autorizar a intervenção deste ente, sempre que a questão discutida no processo individual seja atinente a atuação funcional de um de seus membros (GODINHO, 2004, p.831.). Nesse caso, o conflito objeto da demanda, extrapola o interesse das partes e pode causar prejuízo a própria instituição. 
$\mathrm{Na}$ proposta de redimensionamento de Sergio Cruz Arenhart, exclui-se de a necessidade de comprovação de relação jurídica conexa, sugerindo haver interesse jurídico sempre que a decisão influir negativamente na esfera jurídica de terceiros. Assim, demonstrado o prejuízo jurídico, seria possível a intervenção assistencial em processo individual (ARENHART, 2007, p. 431-432).

No pensamento de Fredie Didier Jr., que leva em consideração a ideia aqui discutida sobre precedente judicial, para além da hipótese clássica de interesse jurídico que permite a intervenção de assistente simples, é possível pensar num interesse jurídico que leve em conta uma relação coletiva, visível sobretudo na produção de efeitos vinculantes da ratiodecidendi de um precedente (DIDIER JR., 2011, p.395).

Por fim, considerando os pensamentos acima exposto, Priscila de Jesus tece algumas conclusões:

Primeiro, o interesse jurídico deve ser considerado preenchido quando decorrer do prejuízo que a decisão jurisdicional proferida em processo individual puder ocasionar a esfera jurídica de terceiros. Segundo, esses terceiros podem ser integrantes de uma coletividade que deve ser representada por um legitimado extraordinário coletivo que poderá intervir como assistente simples, desde que demonstrado o interesse jurídico. Terceiro, o legitimado extraordinário coletivo (assistente) não precisa demonstrar a conexão entre a relação estabelecida entre ele e o assistido, apesar de que, em algumas situações, essa conexão pode decorrer de vínculo institucional ou de vínculo estabelecido entre membros de uma categoria ou classe.

\section{III- O ASSISTENTE SIMPLES E O AMICUS CURIAE NA CONSTRUÇÃO DO PRECEDENTE}

A partir da ampliação da noção de contraditório a participação no formação do precedente pode se dar por meio de duas das modalidades de intervenção de terceiros: a assistência simples e o amicus curiae, além de ser possível a realização previa de audiências públicas. Esses três mecanismos têm previsão para o procedimento de formação de precedente no $§ 2^{\circ}$ do artigo do artigo 926.

A expressão "pessoas, órgãos ou entidades que possam contribuir para a rediscussão da tese" parece se aplicar tanto ao amicuscuriae(comumente indicado pela doutrina) como para o assistente simples, embora ênfase maior esteja sendo dada à intervenção doamicuscuriae. 
De fato,parece razoável os questionamentos acerca da necessidade de intervenção do assistente simples (quando já existe a figura do amicuscuriae)eacerca dasdiferenças existentes entre os institutos, haja vista ambos os instrumentos possibilitarem a democratização do precedente judicial.

A locução amicuscuriae retrata bem o papel do instituto no processo, isto é, o de auxiliar o magistrado em situações que exijam um conhecimento técnico. Nas palavras de Fredie Didier Jr., "trata-se de uma intervenção provocada pelo magistrado ou requerida pelo próprio amicuscuriae, cujo objetivo é o de aprimorar ainda mais as decisões proferidas pelo Poder Judiciário” (DIDIER JR., 2011, p. 409).

Nesse sentido, a sua principal função é a de disponibilizar ao juiz elementos de fato ou de direito que, por estarem relacionadas com o objeto do caso, podem corroborar para um melhor juízo (BUENO, 2008, p.132).

Este instituto que, no Brasil, teve a sua primeira previsão no Direito Imperial, a partir do Decreto 2.684, de 23.10.1875 (que instituiu o Instituto da Ordem dos Advogados, os Tribunais do Comércio e os "jurisconsultos de melhor nota" como amicicuriae na formação de assentos) (DIDIER JR, 2013, p. 4), hoje tem previsão geral no artigono art. 138 do CPC.

Dispõe que o magistrado, considerando a relevância da matéria, a especificidade do tema ou a repercussão social da controvérsia, poderá, exoficcio, ou a requerimento da parte ou daquele que pretende se manifestar, solicitar ou permitir a participação de pessoa natural ou jurídica, órgão ou entidade especializada, com representatividade adequada.

Vê-se, com isso, que a figura do amicuscuriae passa a ter previsão geral, podendo se configurar em qualquer grau de jurisdição, seja qual for o tipo de processo, se de caráter objetivo ou não. Aliás, esse já era posicionamento de Maia Nunes que, ao defender a intervenção do "amigo da corte" em processos subjetivos, salientava que "respeitadas as notórias diferenças entre os sistemas de civil law e common law, não custa lembrar que, na origem, o amicuscuriae atuava justamente nos processos individuais, de parte" (NUNES, 2013, p. 539).

O caput do art. 138 do CPC estabelece que, tanto a pessoa física, quanto a pessoa jurídica, podem atuar como amicuscuriae, desde que com representatividade adequada. Andou bem o legislador nesse ponto, pois, além de deixar claro que pessoas naturais ou jurídicas podem intervir como amigo da corte, também mitiga a possibilidade de qualquer sujeito ingressar na demanda alegando uma das hipóteses acima mencionadas. 
Semelhantemente, a Lei 9868/99 também exige este requisito quando menciona a necessidade de "representatividade dos postulantes".

Nesse ponto, é importante salientar que se entende por representatividade adequada a qualidade do representante para defender, de modo eficiente, os interesses em jogo da sociedade ou grupo por ele representado (FORNACIARI, 2010, p. 50). Isso significa que o amigo da corte não deverá apenas ser um sujeito que reúna um contingente significativo de simpatizantes (DALL'AGNOL JR., 2010, p. 118), mas também deverá demonstrar que congrega em si capacidade e recursos suficientes para levar a juízo os argumentos de determinada coletividade.

A assistência é espécie de intervenção voluntária ou espontânea. Malgrado o CPC de 1973 não abordasse o instituto no título reservado à intervenção de terceiros, o apuro técnico do legislador do novo CPC corrigiu essa falha há muito criticada pela doutrina pátria. Por certo, não restam dúvidas quanto à natureza interventiva da assistência.

A assistência simples é modalidade de intervenção ad coadjuvandum, uma vez que o terceiro (assistente) ingressa na relação processual com o objetivo de auxiliar uma das partes (assistido) (DIDIER JR, 2011, p. 356). Dessa forma, a intervenção não amplia o objeto litigioso do processo, uma vez que o assistente somente adere à pretensão de uma das partes de modo a auxiliá-la por meio de novos argumentos que fortaleçam as suas possibilidades de se tornar vitoriosa na controvérsia (DINAMARCO, 2009, p. 395-396).

Assim como no recurso de terceiro, o que autoriza a intervenção do assistente é a iminência de prejuízo que o mesmo poderá vir a experimentar por causa do resultado negativo que uma das partes, com quem mantém um vínculo jurídico, poderá ter na relação processual sob apreciação do magistrado. O prejuízo alegado há de ser jurídico, apto a demonstrar, consequentemente, o interesse jurídico do assistente. Com isso, se conclui que o simples fato do terceiro sofrer prejuízos de ordem meramente econômica e afetiva não é suficiente para lhe autorizar a ingressar no feito por meio desse instituto.

$\mathrm{Na}$ formação do precedente, o assistente atua de modo a auxiliar na construção de entendimento que lhe seja favorável, de maneira que o seu processo futuro (ou de quem representa) seja influenciado positivamente, acolhendo a tese jurídica em seu benefício.

Por se exigir do amicus curiae certo grau de conhecimento técnico sobre a matéria discutida alguns doutrinadores tem entendido que a sua atuação deve se dar de modo 
imparcial. No caso do assistente simples, porém, ele atuaria com visível parcialidade no auxílio de uma das partes, bem como teria poderes muito mais amplos do que o amicus.

No entanto, a parcialidade não pode ser apontada como a diferença entre o assistente e o amicus curiae. Na prática, verifica-se que boa parte das pessoas e entidades que atuam como amicus possuem certo grau vinculação subjetiva, que, rigorosamente, retira essa isenção.

Em casos assim, a melhor solução é garantir que o polo oposto também tenha um representante, o que faz com que haja paridade de argumentos. Acerca da questão vale a menção à lição de Daniel Neves:

Apesar da origem do instituto estar atrelada a ideia de "amigo da corte" (friendofcourt ou FreunddesGerichts), é preciso reconhecer que demandar um total desinteresse do amicuscuriae seria o suficiente para aniquilar completamente essa forma de participação na ação direta de inconstitucionalidade. É preciso reconhecer que o amicuscuriae contribui com a qualidade da decisão dando sua versão a respeito da matéria discutida, de forma que ao menos o interesse para a solução da demanda no sentido de sua manifestação sempre existirá. Ainda que tenha muito a contribuir em razão de seu notório conhecimento a respeito da matéria, não é comum que as manifestações do amicus curiae sejam absolutamente neutras.

$\mathrm{Na}$ verdade, nem mesmo nos Estados Unidos, país de common lawe onde os juízes permitem a ampla participação de amicuscuriae, tem-se exigido imparcialidade em suas manifestações. No caso Paterson v. McLeanCredit Union, como aponta Antônio Cabral, 112 entidades privadas, 47 procuradores estaduais, 66 senadores dentre outros grupos foram admitidos como amici curiae (CABRAL, 2018, p. 114). As sociedades, associações civis e grupos de pressão (lobby)que participam defendendo interesse da classe que representa (CABRAL, 2018, 114). Não é diferente em relação aos Estados e parlamentares.

De outro lado, a amplitude de poderes realmente pode ser apontada como uma diferença real entre a intervenção do assistente simples e do amicus curiae na construção do precedente judicial. O próprio CPC e a Lei 9868/99, acolhendo entendimento há muito consolidado no Supremo Tribunal Federal (ADI 2581 AgRg/SP, rel. Min. Maurício Corrêa), veda a interposição de recursos pelo amicus curiae, ressalvados os embargos de declaração.

Os poderes do amicus curiae estão condicionados à benevolência do magistrado, cabendo-lhe, na decisão que solicitar ou admitir a intervenção, definir quais são estes poderes. A própria decisão que indefere a intervenção do amicus curiae é irrecorrível. Essa realidade só muda no incidente de resolução de demandas repetitivas - IRDR, que permite a 
interposição de recurso contra a decisão final e no caso da Comissão de Valores Mobiliários CVM, por expressa permissão do $§ 3^{\circ}$ do art. 31 da Lei n. 6.385/1976.

É possível, inclusive, que a atuação do amicus curiae se reduza a manifestação por escrito. Como exemplo, a prática jurisprudencial do próprio STF reduziu o instituto à mera apresentação de memoriais ou à prestação de informações por muito tempo.

O assistente, porém, por sua própria natureza, tem amplos poderes, os quais decorrem diretamente da lei e não se condicionam a nenhuma permissão do juiz. Uma vez preenchida a hipótese e não havendo vedação legal ou impugnação, o assistente deve ser admitido. A possibilidade de rejeição liminar se limita às vedações legais, como em causa regida pelo Código de Defesa do Consumidor.

Pelo teor do artigo 121 do CPC, o assistente simples exercerá os mesmos poderes e sujeitar-se-á aos mesmos ônus processuais que o assistido.Poderá interpor qualquer recurso permitido ao assistido, inclusive quando este não recorrer; produzir provas; arguir impedimento ou suspeição do magistrado; entre outros.

Quanto antes se der a intervenção assistencial, mais ampla será a possibilidade de influência, recebendo o assistente o processo no estado em que se encontre em qualquer procedimento e em todos os graus de jurisdição. Assim, se o assistente demora a intervir, os seus poderes realmente podem ser iguais ou inferiores ao do amicuscuriae.

Como exemplo, se em um processo que tramita desde o primeiro grau de jurisdição o assistente deixa para intervir somente no exame do recurso extraordinário, ainda que busque participar da formação do precedente, não poderá produzir provas ou discutir o reexame dessas, como aponta o enunciado no 279 da súmula da jurisprudência do STF. Ainda assim, caso seja demonstrada a negligência da parte, é possível arguir a exceptio male gestis processos, prevista no artigo 123, I e II do CPC.

Percebendo essa amplitude de poderes que o assistente tem se comparado ao amicuscuriae, inclusive no sistema concentrado de formação de precedentes, o próprio legislador previu que as partes dos demais processos participarão do IRDR como assistente simples.

Por outro lado, há de se entender que para a intervenção do assistente ocorrer com fundamento na construção do precedente judicial existem maiores requisitos que os necessários à intervenção do amicuscuriae. Isso porque somada a necessidade de representatividade adequada, relevância da matéria, especificidade do tema e a repercussão 
social da controvérsia, é necessário que seja demonstrada uma relação jurídica coletiva entre assistente, o assistido e os demais representados.

Este requisito pode ser visualizado a partir do precedente judicial formado em questão de ordem no Recurso Extraordinário n. 550.769 QO/RJ. Este hard case decidido pelo Supremo Tribunal Federal, se antecipando às discussões doutrinárias, permitiu, em 2008, o ingresso do Sindicato da Indústria de Fumo do Estado de São Paulo como assistente simples em processo pendente.

Por certo, se o sindicato fosse titular de uma relação conexa com a discutida no caso, seria esta uma situação absolutamente comum. No entanto, não havia tal relação e a única explicação para essa admissão foi o reconhecimento de interesse jurídico na formação da orientação jurisprudencial que seria firmada pelo caso.

O processo discutia a constitucionalidade do Decreto-lei 1.593 de 1997, que estabelecia uma rigorosa exigência de regularidade fiscal para a continuidade do registro especial que permite a fabricação e a comercialização de cigarros.

Nos termos do voto do relator, no entanto, parece ser insuficiente o simples interesse na formação da ratiodecidendi a ser firmada no julgado, sendo necessário, outrossim, verificar a relação jurídica coletiva que aquele processo mantinha com os sujeitos representados pelo SINDIFUMO.

É o que se percebe do trecho a seguir transcrito:

Reconheço que o mero interesse na resolução da demanda, como forma de firmar orientação jurisprudencial que eventualmente será útil ou desastrosa a determinado sujeito de direito é insuficiente para que se repute presente interesse jurídico de intervenção em processo judicial. Contudo, registro que já é assistente simples nos autos o Instituto Etco, que vem procurando demonstrar o grave desequilíbrio concorrencial que poderia ocorrer se a inconstitucionalidade do Decreto-lei for reconhecida. Portanto, o interesse jurídico do Sindifumo-SP encontra amparo na manifesta necessidade de pluralização do debate, concorrendo com os elementos que julgar úteis à melhor compreensão do quadro em exame e forem processualmente admissíveis neste estágio do processo.

Analisando o precedente em questão, Fredie Didier e Leonardo da Cunha lecionam que "a relação jurídica conexa à relação discutida, aqui, é uma relação jurídica coletiva, pois envolve a proteção de direitos individuais homogêneos, cuja titularidade pertence à coletividade das vítimas (no caso, as indústrias de tabaco)” (DIDIER JR., 2016, p. 608).

Ao proceder assim o STF impõe limites à participação do assistente simples na construção da tese, estabelecendo que para atuar nesta condição não basta alegar interesse 
jurídico, faz-se necessário que o próprio interveniente tenha uma relação de direito coletivo com o grupo, categoria ou classe possivelmente prejudicados pela orientação.

Avança-se ao reconhecer, neste precedente, que o interesse jurídico justificador da intervenção do assistente simples ou do amicuscuriae pode estar relacionado aratiodecidendia ser formada em um caso concreto, mormente daqueles que são julgados pelo STF e que possuem condão de gerar precedentes com força vinculantes, havendo o que tem sido chamado de "redefinição do pressuposto do interesse jurídico", porém impõe-se limite cuja razão é evitar o tumulto processual e a inobservância do princípio da duração razoável do processo (DIDIER JR., 2016, p. 608).

Já havia intervenção semelhante à ocorrida neste precedente, porém na qualidade de amicuscuriae que, como se vê, distingue-se da assistência. Não parece existir outro caso em que esse tipo de intervenção assistencial tenha acontecido, malgrado as vantagens que proporciona.

De outro lado, há previsão expressa na seara trabalhista quanto a possibilidade de intervenção de terceiros na qualidade de assistente simples no julgamento de recurso de revista repetitivo, sendo interessante, inclusive, a transcrição do art. 896-C da CLT:

Art. 896-C. Quando houver multiplicidade de recursos de revista fundados em idêntica questão de direito, a questão poderá ser afetada à Seção Especializada em Dissídios Individuais ou ao Tribunal Pleno, por decisão da maioria simples de seus membros, mediante requerimento de um dos Ministros que compõem a Seção Especializada, considerando a relevância da matéria ou a existência de entendimentos divergentes entre os Ministros dessa Seção ou das Turmas do Tribunal.

§ 8o O relator poderá admitir manifestação de pessoa, órgão ou entidade com interesse na controvérsia, inclusive como assistente simples, na forma da Lei no 5.869, de 11 de janeiro de 1973 (Código de Processo Civil).

Em sentido diametralmente oposto, o STJ tem entendido que não é cabível a intervenção de ente coletivo em processo em curso haja vista que "o interesse institucional, não obstante encerre também interesse jurídico para a propositura da ação coletiva, não enseja a intervenção 'ad adjuvandum' em processo 'inter partes' (STJ, ia T., REsp 821.586/PR, rel. Min. Luiz Fux, j. 7/102008, DM 3/11/2008).

Na verdade, este é um precedente anterior ao Código de Processo Civil de 2015, sendo importante que a Corte torne a se manifestar sobre a questão à luz do sistema de valores previsto no novo código de ritos, que nitidamente se afasta do modelo individualista do revogado Código de Buzaid. 
O caráter publicista de processo, inclusive, faz com que haja uma nítida diferença entre a assistência simples tradicional e essa que visa discutir a tese jurídica. Nesta, o assistente poderá recorrer ou praticar ato que vise fortalecer os argumentos favoráveis aos seus representados mesmo se o assistido manifestar interesse em desistir.

Como a tese não diz respeito somente ao indivíduo, mas sim a uma coletividade, não pode a parte dispor dela como bem entender. Pode até abrir mão de seu direito individual posto em litígio, mas a discussão dos argumentos que formarão o precedente deve continuar se o assistente praticar os atos necessários.

A razão se assemelha à que orienta os processos de controle concentrado de constitucionalidade ou os incidentes de resolução de demandas repetitivas. Embora o processo não seja objetivo, o interesse público se sobrepõe ao interesse individual posto em causa.

\section{CONSIDERAÇÕES FINAIS}

Dito isto, não restam dúvidas quanto à necessidade de concretização do princípio democrático nos procedimentos de construção do precedente judicial. Isso passa pela releitura do princípio do contraditório, que ampliado a um nível maior de participação substantiva, com a intervenção do assistente simples e do amicuscuriae, aperfeiçoa o debate em torno da tese a ser formada.

Ao lado das audiências públicas e de outras formas de consulta popular, essas duas modalidades de intervenção de terceiro, permite ao órgão jurisdicional considerar o maior número de argumentos possíveis na sua decisão, que, além de resolver o caso concreto, projeta a sua fundamentação determinante para outros processos.

A intervenção do assistente simples e do amicuscuriaenessa hipótese, porém, além de possuir requisitos distintos,provoca atuações também diferentes. Os poderes do assistente simples, que se assemelham aos poderes das partes, são nitidamente mais amplos que os exercidos pelo amicuscureae.

Pelo interesse público na construção do precedente, inclusive, é possível se cogitar na possibilidade de prática de atos processuais, como a interposição de recurso, mesmo contra a vontade do assistido, se este estiver negligenciando, renunciando ou desistindo do processo. Se assim ocorrer, o ato praticado só deverá influir na tese, sendo preservadaavontade da parte que deseja abrir mão de seu direito em juízo. 
Sendo assim, esta modalidade de intervenção deve ser melhor explorada, não havendo razões plausíveis à sua inutilização no momento da formação do precedente judicial, existindo, destarte, precedente do próprio Supremo Tribunal Federal admitindo essa modalidade quando haja a necessidade de pluralizar o debate.

\section{REFERÊNCIAS}

ARENHART, Sérgio Cruz. O Recurso de Terceiro Prejudicado e as Decisões Vinculantes. In: NERY JR., Nelson; WAMBIER, Teresa Arruda (coord). Aspectos Polêmicos e Atuais dos Recursos Cíveis e Afins. São Paulo: Revista dos Tribunais, 2007, p. 425.

BARBI, Celso Agrícola. Comentários ao Código de Processo Civil. v. 1. Rio de Janeiro: Forense, 1975, p. 513; CABRAL, Antonio do Passo . El principio delcontradictorio como derecho de influencia y deber de debate. In: Revista Peruana de DerechoProcesal, v. XIV, p. 266, 2010.

BUENO, Cássio Scarpinella. Quatro Perguntas e Quatro Resposta Sobre o AmicusCuriae. In: Revista da Escola Nacional da Magistratura. ano 3, n. 5, maio de 2008, p.132.

CABRAL, Antonio do Passo. Pelas asas de Hermes: a intervenção do amicuscuriae, um terceiro especial. Revista de Direito Administrativo, Rio de Janeiro, v. 234, p. 111- 42, out. 2003. ISSN 2238-5177. Disponível em: <http://bibliotecadigital.fgv.br/ojs/index.php/rda/article/view/45149>. Acesso em: 05 Fev. 2018. doi:http://dx.doi.org/10.12660/rda.v234.2003.45149, p. 114.

CABRAL, Antônio do Passo. Nulidades no Processo Moderno: contraditório, proteção da confiança e nulidade prima facie dos atos processuais. Rio de Janeiro: Forense, 2010, p. 104.

COELHO, Marcus Vinicius Furtado. O Contraditório Cooperativo no Novo Código de Processo civil. In: Revista de Informação Legislativa, v. 48, n. 190 t.2, p. 46, abr./jun. 2011. Disponível em <http://www2.senado.leg.br/bdsf/item/id/242943> Acessado em: 24/06/2015.

DALL'AGNOL JR., Antônio Janyr; USTÁRROZ, Daniel; PORTO, Sérgio Gilberto. Afirmação do amicuscuriae no direito brasileiro. In: DIDIER JR, Fredie (Coord). et al. $O$ Terceiro no Processo Civil Brasileiro e Assuntos Correlatos: estudos em homenagem ao professor Athos Gusmão Carneiro. São Paulo: Revista dos Tribunais, 2010, p. 118.

DIDIER JR, Fredie. Curso de Direito Processual Civil: introdução ao direito processual civil e processo de conhecimento. 13. ed. Salvador: Juspodvm, 2011, p. 56.

; CUNHA, Leonardo carneiro da. Curso de Direito Processual Civil. Curso de direito processual civil: o processo civil nos tribunais, recursos, ações de competência originária de 
tribunal e querela nullitatis, incidentes de competência. 13. ed. reform. v. 3. Salvador: Juspodvim, 2016, p. 608.

; SOUZA, Marcus Seixas. Formação do precedente e amicuscuriae no direito imperial brasileiro: o interessante dec. 6.142/1876. Revista de Processo, vol. 220/2013, Jun / 2013.

DINAMARCO, Cândido Rangel. Instituições de Direito Processual Civil. v. 2. 6. ed. São Paulo: Malheiros, 2009, p. 395-396.

, Cândido Rangel. Fundamentos do Processo Civil Moderno. 2. ed. São Paulo: Revista dos Tribunais, 1987. p. 90.

FORNACIARI, Flávia HellmeisterClito. Representatividade adequada nos processos coletivos. Tese de Doutorado orientada pela professora Ada Pellegrini Grinover a apresentada à Faculdade de Direito da USP. São Paulo: Faculdade de Direito da USP, 2010, p. 50.

GODINHO, Robson Renault. Ministério Público e assistência: o interesse institucional como expressão do interesse jurídico. In: DIDIER JR., Fredie; WAMBIER, Teresa Arruda Alvim (coord.). Aspectos polêmicos e atuais sobre os terceiros no processo civil e assuntos afins. São Paulo: Revista dos Tribunais, 2004, p.831.

GONÇALVES, Marcelo Barbi. O Incidente de Resolução de Demandas Repetitivas e a Magistratura Deitada. Revista de Processo, 2013, p. 209.

JESUS, Priscilla Silva de. Precedente judicial e a nova compreensão do interesse processual. Dissertação mestrado em Direito) - Faculdade de Direito, Universidade Federal da Bahia, p. 216-223, 2014.

MITIDIERO, Daniel Francisco. Colaboração no Processo Civil. São Paulo: Revista dos Tribunais, 2009, p. 102-103).

A Multifuncionalidade do Direito Fundamental ao Contraditório e a improcedência limitar (art. 285-A, CPC): resposta à crítica de José Tesheiner. In: Revista de Processo, ano 32, n. 144, p. 108-109, fev. 2007.

NUNES, Jorge Amaury Maia. Mandado de Injunção e AmicusCuriae in Mandado de Injunção: estudos sobre sua regulamentação. Editora Saraiva, 2013, p. 539.

WAMBIER, Tereza Arruda; MEDINA, José Miguel Garcia. Amicus curiae. In: DIDIER JR, Fredie (Coord). et al. O Terceiro no Processo Civil Brasileiro e Assuntos Correlatos: estudos em homenagem ao professor Athos Gusmão Carneiro. São Paulo: Revista dos Tribunais, 2010, p. 494. 